\title{
Beclin1 overexpression suppresses tumor cell proliferation and survival via an autophagy-dependent pathway in human synovial sarcoma cells
}

\author{
JIALIN ZHU ${ }^{1}$, YONGSONG CAI $^{1}, \mathrm{KE} \mathrm{XU}^{1}, \mathrm{XIAOYU} \mathrm{REN}^{1}$, JIAN SUN $^{2}$, \\ SHEMIN $\mathrm{LU}^{2}$, JINGHONG CHEN ${ }^{3}$ and PENG XU ${ }^{1}$ \\ ${ }^{1}$ Department of Joint Surgery, Xi'an Hong Hui Hospital, Xi'an Jiaotong University Health Science Center, Xi'an, \\ Shaanxi 710054; ${ }^{2}$ Department of Genetics and Molecular Biology, Xi'an Jiaotong University Health Science Center, \\ Xi'an, Shaanxi 710061; ${ }^{3}$ Key Laboratory of Trace Elements and Endemic Diseases of National Health and \\ Family Planning Commission, Institute of Endemic Diseases, School of Public Health, \\ Xi'an Jiaotong University Health Science Center, Xi'an, Shaanxi 710061, P.R. China
}

Received January 29, 2018; Accepted July 17, 2018

DOI: $10.3892 /$ or.2018.6599

\begin{abstract}
Beclin1 is an important autophagy-related protein, which is involved in both autophagy and apoptosis. In recent years, the antitumor effect of Beclin1 has received increased attention. In the present study, we established a stable Beclin1-overexpressing cell line with SW982 human synovial sarcoma cells. We found that Beclin1 overexpression decreased the cell viability, inhibited proliferation and induced apoptosis in SW982 cells. The expression levels of Bcl-2 and PCNA were decreased, while the levels of cleaved-caspase-3 and cleaved-PARP were increased. Beclin1 is closely related with autophagy, thus the autophagy-related markers LC3 and p62 were detected by western blot analysis, and transmission electron microscopy was used to observe autophagosomes. The results showed that the expression level of LC3II was increased and that of p62 was decreased. Moreover, many double membrane-enclosed autophagosomes were found in cells with Beclin1 overexpression, which indicated that the autophagic activity was enhanced. To explore the effect of autophagy on the viability of SW982 cells, Atg5 was knocked down using siRNA to inhibit the autophagic activity. We found that autophagy contributed to the decrease in cell viability. Knockdown of Atg5 increased the viability and decreased the apoptotic rate of SW982 cells with Beclin1 overexpression. The expression level of Bcl-2 was increased, while the expression levels of cleaved-caspase-3 and cleaved-PARP
\end{abstract}

Correspondence to: Professor Peng Xu, Department of Joint Surgery, Xi'an Hong Hui Hospital, Xi'an Jiaotong University Health Science Center, 555 Friendship East Street, Xi'an, Shaanxi 710054, P.R. China

E-mail: sousou369@163.com

Key words: Beclin1, proliferation, autophagy, apoptosis, synovial sarcoma were decreased. We also found that the Akt/Bcl-2/caspase-9 pathway was involved. The phosphorylation of AKT was positively correlated with cell viability. The cleavage of caspase-9 was increased by Beclin1 overexpression and decreased by inhibition of autophagy. Altogether, our results suggested that both autophagy and apoptosis contributed to the antitumor effect of Beclin1 in SW982 cells.

\section{Introduction}

Synovial sarcoma (SS) is a malignant soft tissue tumor that originates from synovial cells or mesenchymal cells that differentiate into synovial cells (1). The symptoms of SS are pain and a localized mass at an early stage, and joint damage can be found when the tumor progresses. Many patients are diagnosed at an advanced stage because of the atypical symptoms and the rapid progression of the tumor (2). Sustained proliferation of the tumor cells combined with insufficient apoptosis plays an important role in tumor progression. Therefore, it is of great importance to reveal the underlying mechanism that regulates the proliferation and apoptosis of tumor cells.

Autophagy is an evolutionarily conserved response at the subcellular level. Autophagy degrades the cytoplasm and organelles, releases amino acids and fatty acids, and plays an important role in metabolism and organelle renewal in cells (3). Normally, autophagy adapts cells to the environment to help cells survive tough conditions. Notably, autophagy may function as an alternative cell death mechanism, similar to apoptosis under certain conditions, which is described as type II programmed cell death (4). Autophagy is closely related to carcinogenesis and tumor progression. Aberrant expression of autophagic genes, changes in autophagic activity and conversion of autophagic signaling pathways can affect the viability of tumor cells (5).

The Beclin1 gene, also known as BECN1, is an essential gene involved in the autophagy process in mammalian cells. Liang et al (6) found a new protein (molecular weight $60 \mathrm{ku}$ ) in rats with encephalitis caused by the fatal Sinbis virus in 1998 
and named the gene that coded this protein Beclin1. Beclin1 is a homologue of yeast Atg6, located on the human chromosome 17q21. Beclin1 codes a sequence with 450 amino acid residues, which contains three special domains: The conserved $\mathrm{BH} 3$ domain (residues 107-135), the coiled coil domain (residues 140-268) and the evolutionarily conserved domain (residues 244-337) (7). Some studies have confirmed that Beclin1 can induce and regulate autophagy by binding to Vps34p through the evolutionarily conserved domain and UVRAG through the coiled coil domain (8). Moreover, the function of Beclin1 in apoptosis has been investigated in many studies. A recent research showed that Beclin1 regulated apoptosis by binding to the anti-apoptotic members of the Bcl family such as Bcl-2, Bcl-xl and Bcl-w through the BH3 domain (9).

The antitumor effect of Beclin1 has been confirmed in many types of tumors such as breast $(10,11)$, colon $(12,13)$, cervical $(14,15)$ ovarian cancer $(16,17)$ and glioblastoma $(18,19)$. Some studies have reported that the expression level of Beclin1 is significantly lower in ovarian cancer tissue than in normal ovarian tissue $(20,21)$; moreover, inhibited proliferation was observed in breast cancer cells with high expression level of Beclin1 $(22,23)$. However, the underlying mechanism by which Beclin1 promotes tumor cell death remains unclear. Some studies have suggested that Beclin1 inhibits the viability of tumor cells by inducing autophagic cell death $(24,25)$; some studies indicate that Beclin1 directly induces the apoptosis of tumor cells in an autophagy-independent manner $(26,27)$. In the present study, we explored the function of Beclin1 in SW982 synovial sarcoma cells and investigated the mechanism by which Beclin1 regulates cell proliferation, apoptosis and autophagy.

\section{Materials and methods}

Cell culture. The human synovial sarcoma cell line SW982 was obtained from the Shanghai Institute of Cell Biology, Chinese Academy of Sciences (Shanghai, China). The SW982 cells were cultured in Dulbecco's modified Eagle's medium (DMEM)/F12 medium (Thermo Fisher Scientific, Inc. Waltham, MA, USA) supplemented with $10 \%$ fetal bovine serum (FBS; Gibco; Thermo Fisher Scientific, Inc.), $100 \mathrm{U} / \mathrm{ml}$ penicillin and $100 \mu \mathrm{g} / \mathrm{ml}$ streptomycin in a humid atmosphere containing $5 \% \mathrm{CO}_{2}$ at $37^{\circ} \mathrm{C}$.

Establishment of stable cell lines overexpressing Beclin1. The lentiviruses expressing the Beclin1 sequence (OE) and the negative control lentiviruses (NC) were constructed by Hanbio Co. (Shanghai, China). The lentiviral vector contains a GFP marker for indicating the transfection efficiency and a puromycin-resistant marker for selecting the transfected cells. The virus titer was raised to $10^{8}$ transfection units $(\mathrm{TU}) / \mathrm{ml}$. Cells were seeded in 6-well plates and infected with viruses and polybrene on the following day. A total of $24 \mathrm{~h}$ later, the medium containing the viruses was removed and replaced with fresh medium. The infected cells were treated with puromycin for 7 days to obtain the positive clones. Positive clones were selected and purified to establish the stable cell line. The expression level of Beclin1 was determined by immunofluorescence staining, RT-qPCR and western blot analysis.
Immunofluorescence staining. Cells were seeded in 24-well plates and maintained for $48 \mathrm{~h}$. After being washed 3 times with phosphate-buffered saline (PBS), cells were fixed in a 4\% paraformaldehyde solution for $15 \mathrm{~min}$, permeabilized with $0.3 \%$ Triton X-100, blocked with 5\% BSA blocking reagent for $30 \mathrm{~min}$ and then incubated with the anti-Beclin1 monoclonal primary antibody (dilution 1:50; cat. no. BM5181; Wuhan Boster Biological Technology, Ltd., Wuhan, China) overnight at $4^{\circ} \mathrm{C}$. After another 3 washes with PBS, the cells were incubated with tetraethyl rhodamine isothiocyanate (TRITC)-conjugated secondary antibody (dilution 1:200; cat. no. BA1090; Wuhan Boster Biological Technology, Ltd.) for $1 \mathrm{~h}$ at room temperature. DAPI reagent was used to counterstain the nuclei. The result of the staining was observed with an inverted fluorescence microscope system (Nikon ECLIPSE Ti-S; Nikon, Tokyo, Japan).

Total RNA extraction and quantitative real-time polymerase chain reaction $(R T-q P C R)$ analysis. Total RNA was extracted from SW982 cells using TRIzol reagent (Invitrogen; Thermo Fisher Scientific, Inc.) according to the manufacturer's instructions. Total RNA was reverse-transcribed into cDNA using a PrimeScript RT reagent kit (Takara Biotechnology, Co., Ltd., Dalian, China). RT-qPCR was performed with the SYBR Premix Ex Taq (Takara Biotechnology, Co., Ltd.). PCR primers were as follows: Forward, 5'-GGTGTCTCTCGCAGATTC ATC-3' and reverse, 5'-TCAGTCTTCGGCTGAGGTTCT-3'. Glyceraldehyde-3-phosphate dehydrogenase (GAPDH) was used as an internal control. The cycling conditions were as follows: The initial denaturation at $95^{\circ} \mathrm{C}$ for $5 \mathrm{~min}$, and followed by 40 cycles at $95^{\circ} \mathrm{C}$ for $15 \mathrm{sec}, 55^{\circ} \mathrm{C}$ for $30 \mathrm{sec}$ and $72^{\circ} \mathrm{C}$ for $30 \mathrm{sec}$. The relative mRNA expression was calculated using the $2^{-\Delta \Delta \mathrm{Cq}}$ method (28).

Western blot analysis. Total protein was isolated using RIPA lysis buffer (Beyotime Institute of Biotechnology, Shanghai, China) supplemented with protease inhibitor cocktail (Beyotime Institute of Biotechnology) on ice, and the concentration of the protein was determined using a BCA protein assay kit (Beyotime Institute of Biotechnology) according to the manufacturer's instructions. Equal amounts of protein lysates (40-60 $\mu \mathrm{g}$ ) were loaded per lane and separated by $8-12 \%$ sodium dodecyl sulfate-polyacrylamide gel electrophoresis (SDS-PAGE), and then electrotransferred onto nitrocellulose membranes (Millipore, Bedford, MA, USA). The membranes were blocked with $5 \%$ skimmed milk for $2 \mathrm{~h}$ at room temperature and then incubated with the following primary antibodies overnight at $4{ }^{\circ} \mathrm{C}$ : Anti-PARP monoclonal antibody (1:1,000 dilution; cat. no. ab32561; Abcam, Cambridge, UK), anti-p62 monoclonal antibody (1:1,000 dilution; cat. no. ab207305; Abcam), anti-PCNA monoclonal antibody (1:500 dilution; cat. no. 13110; Cell Signaling Technology, Inc., Inc., Danvers MA, USA), anti-Atg5 monoclonal antibody (1:1,000 dilution; cat. no. 9980; Cell Signaling Technology, Inc., Inc.), anti-Bcl-2 monoclonal antibody (1:1,000 dilution; cat. no. 4223; Cell Signaling Technology, Inc.), anti-Bax monoclonal antibody (1:1,000 dilution; cat. no. 5023; Cell Signaling Technology, Inc.), anti-Beclin1 monoclonal antibody (1:1,000 dilution; cat. no. ab210498; Abcam), anti- $\beta$-actin monoclonal antibody (1:1,000 dilution; cat. no. 4970; 
Cell Signaling Technology, Inc.), anti-caspase-3 monoclonal antibody (1:1,000 dilution; cat. no. 9665; Cell Signaling Technology, Inc.), anti-cleaved-caspase-3 monoclonal antibody (1:500 dilution; cat. no. 9664; Cell Signaling Technology, Inc.), anti-caspase-9 monoclonal antibody (1:500 dilution; cat. no. ab32539; Abcam), anti-LC3 monoclonal antibody (1:1,000 dilution; cat. no. 12741; Cell Signaling Technology, Inc.), anti-Akt monoclonal antibody (1:1,000 dilution; cat. no. ab179463; Abcam) and anti-phospho-Akt (Ser-473) monoclonal antibody (1:1,000 dilution; cat. no. ab81283; Abcam). After being washed with TBST buffer (Tris-buffered saline supplemented with Tween-20) 3 times (10 min for each time), the membranes were incubated with goat anti-rabbit horseradish peroxidase-conjugated secondary antibody (1:5,000 dilution; cat. no. BA1055; Wuhan Boster Biological Technology, Ltd.) for $1 \mathrm{~h}$ at room temperature. After another 3 washes, the proteins that had bound with the antibodies were visualized with an enhanced electrochemiluminescence (ECL) system (GeneTools software version 4.03.05.0; Synoptics Ltd., Cambridge, UK).

Cell viability assay. The viability of the cells was detected using the Cell Counting Kit-8 (CCK-8) assay. Cells were seeded in 96-well plates $\left(10^{4}\right.$ cells/well) and allowed to adhere overnight before the assay. At 24, 48 and 72 h, $10 \mu \mathrm{l}$ of CCK-8 reagent (Nanjing KeyGen Biotech, Co., Ltd., Nanjing, China) was added to each well and incubated for $4 \mathrm{~h}$. The optical density (OD) values were measured at a wavelength of $450 \mathrm{~nm}$ with a microplate reader (Thermo Fisher Scientific, Inc.).

EdU cell proliferation assay. The proliferation of cells was detected using EdU cell proliferation assay according to the manufacturer's instructions. Cells were seeded in 24-well plates and maintained for $48 \mathrm{~h}$ before the assay. A total of $500 \mu \mathrm{l}$ EdU (10 $\mu \mathrm{M})$ reagent (Biotime, Shanghai, China) was added to each well and incubated for $4 \mathrm{~h}$ to label the cells. After 3 times washing with PBS, cells were fixed in a $4 \%$ paraformaldehyde solution for $15 \mathrm{~min}$, permeabilized with $0.3 \%$ Triton X-100 for another $15 \mathrm{~min}$, and then incubated with the click-reaction reagent for $30 \mathrm{~min}$ at room temperature in the dark. DAPI reagent was used to counterstain the nucleus. The result of staining was observed with a fluorescence inversion microscope system (Nikon ECLIPSE Ti-S; Nikon, Tokyo, Japan).

Cell apoptosis assay. An Annexin V-PE/7-AAD apoptosis detection kit (Nanjing KeyGen Biotech) was used according to the manufacturer's instructions to measure the apoptotic rate of cells. Cells $\left(10^{6}\right.$ cells/well $)$ were seeded into 6 -well plates and allowed to adhere overnight. After being cultured for $48 \mathrm{~h}$, cells (including the floating ones) were harvested and washed twice with PBS, and then resuspended with $400 \mu \mathrm{l}$ Annexin $\mathrm{V}$ binding buffer at a density of $4 \times 10^{5}$ cells $/ \mathrm{ml}$. Subsequently, the cells were incubated with phycoerythrin (PE) labelled Annexin V for $15 \mathrm{~min}$ at room temperature in the dark, and then with 7-amino-actinomycin D (7-AAD) for another $5 \mathrm{~min}$ on ice in the dark. Flow cytometry (Guava easyCyte HT; EMD Millipore, Temecula, CA, USA) was applied to distinguish early apoptotic, late apoptotic, necrotic and viable cells.
Plate clone formation assay. Cells were seeded and maintained in 6-well plates at a density of 200 cells/well. A total of $10 \mathrm{ml}$ of medium was added into each well to supply sufficient nutrition for clone formation. After 3 weeks, cells were fixed in a $4 \%$ paraformaldehyde solution for $30 \mathrm{~min}$, and then stained with Giemsa dye. The quantity and diameter of the clones were considered as the evaluating indicators of the proliferation ability of the cells (Nikon d610 camera; Nikon).

Transmission electron microscopy. Cells were fixed with ice-cold $2 \%$ glutaraldehyde and then $1 \%$ osmium tetroxide. After 2 washes with PBS and dehydration with gradient ethanol (30-100\%), the cells were embedded in propylene oxide/embedding resin (1:1). The resin blocks were cut into ultra-thin $(60 \mathrm{~nm})$ sections with a LKB-V ultramicrotome (LKB, Broma, Sweden). The sections were fixed on 200 mesh copper standard grids and stained with uranyl acetate and lead citrate. The cell ultrastructure was observed through an $\mathrm{H}-7650$ transmission electron microscope (Hitachi, Ibaraki, Japan).

RNAi experiment. Small interfering RNA (siRNA) targeting Atg5 and control siRNA were synthesized by Shangha GenePharma Co.,Ltd.(Shanghai, China). The siRNA sequences were as follows: 1\#siRNA, 5'-GACGUUGGUAACUGACAA ATT-3'; 2\#siRNA, 5'-GUCCAUCUAAGGAUGCAAUTT-3'; 3\#siRNA, 5'-GACCUUUCAUUCAGA AGCUTT-3'; and control siRNA, 5'-TTCTCCGAACGTGTCACGTTT-3'.

SW982 cells were seeded in 6-well plates at a density of $5 \times 10^{5}$ cells/well and allowed to adhere for $24 \mathrm{~h}$. Then, the cells were transfected with Atg5 siRNA or control siRNA. X-tremeGENE siRNA Transfection reagent (Roche Diagnostics, Mannheim, Germany) was used to improve the transfection efficiency, according to the manufacturer's protocol. The suppressing efficiency on Atg5 was determined by RT-qPCR and western blot analysis.

Statistical analysis. Statistical analysis was performed using the SPSS software version 18.0 (SPSS, Inc., Chicago, IL, USA). Data are presented as the means \pm standard deviation (SD). All data were analyzed with one-way ANOVA tests followed by Tukey's correction for multiple comparisons. All statistical tests were two-sided, and $\mathrm{P}<0.05$ was considered to indicate a statistically significant result.

\section{Results}

A stable Beclin1-overexpressing cell line is established. We established the Beclin1-overexpressing SW982 cells and selected the stable cells. We divided the SW982 cells into 3 groups: Control, NC (transfected with the negative control lentivirus) and $\mathrm{OE}$ (Beclin1-overexpressing) groups. The expression level of Beclin1 in each group was detected by RT-qPCR (Fig. 1A), immunofluorescence staining (Fig. 1B) and western blot analysis (Fig. 1C). The results indicated that the expression level of Beclin1 was significantly increased in the OE group compared to that noted in the Control and NC groups. No significant difference was observed between the Control and NC groups. 

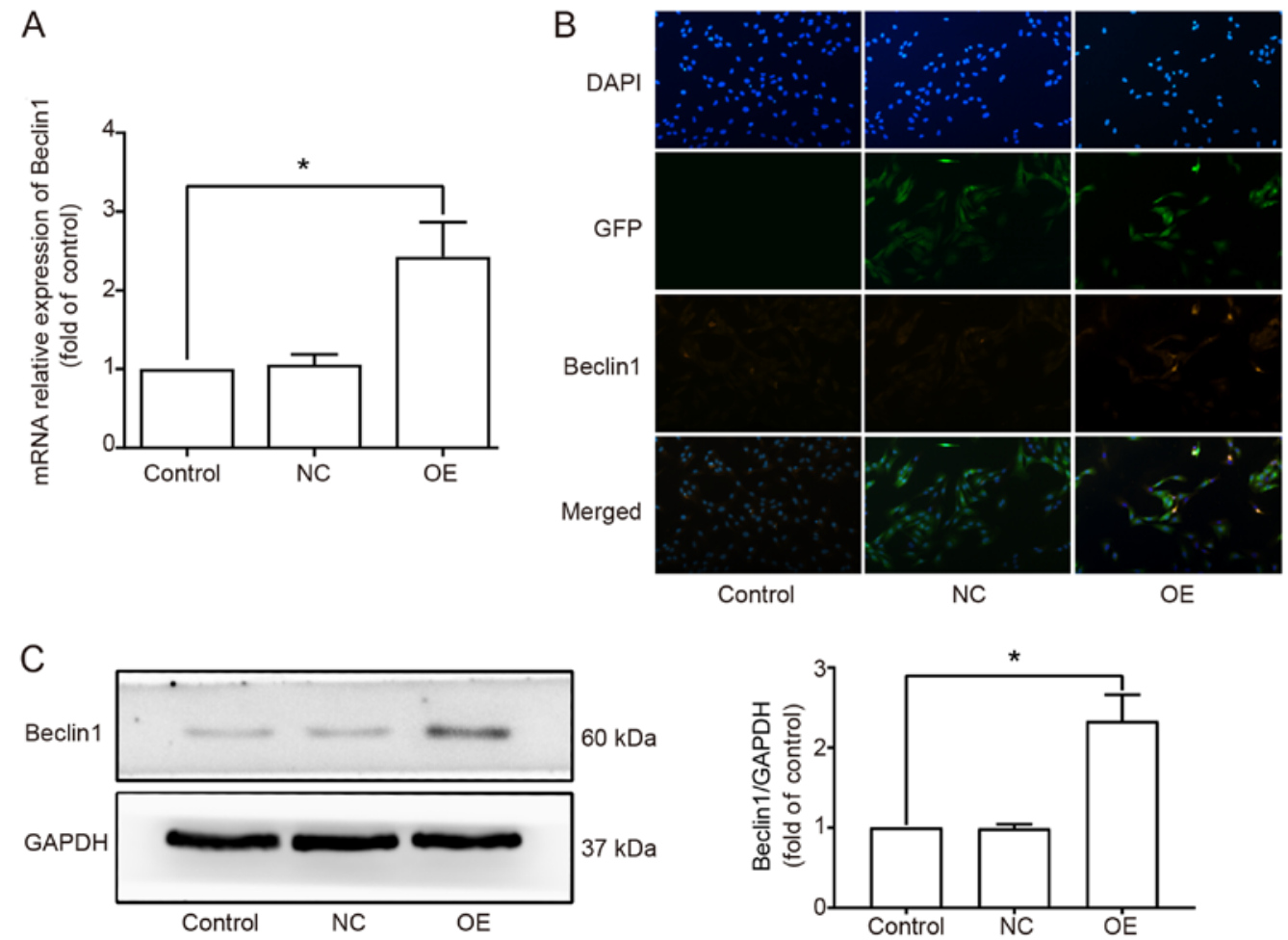

Figure 1. The expression level of Beclin1 in the 3 groups: Control, NC (transfected with the negative control lentivirus) and OE (Beclin1-overexpressing) groups. (A) RT-qPCR analysis of Beclin1 expression. (B) Immunofluorescence staining of Beclin1 (magnification, x100). (C) Western blot analysis of Beclin1. ${ }^{*} \mathrm{P}<0.05$ compared to the Control group.

A

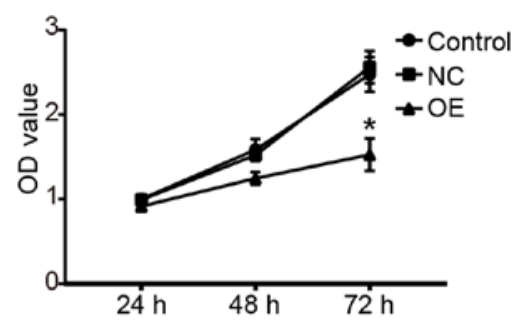

C

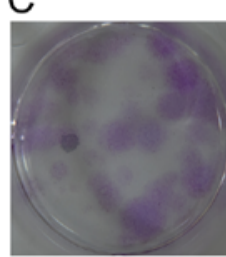

Control

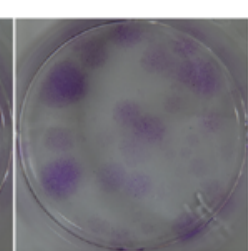

NC

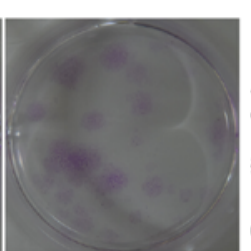

OE
B
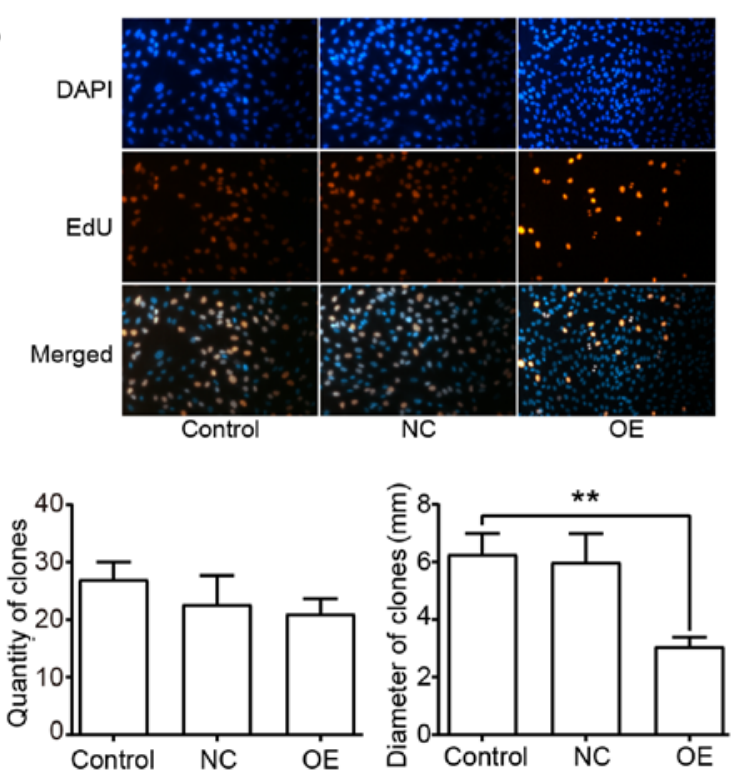

Figure 2. The effect of Beclin1 overexpression on the viability and proliferation of SW982 cells. (A) The CCK-8 assay in the 3 groups: Control, NC (transfected with the negative control lentivirus) and OE (Beclin1-overexpressing). (B) The EdU cell proliferation assay in the 3 groups (magnification, $\mathrm{x} 100)$. (C) The plate clone formation assay in the 3 groups. ${ }^{*} \mathrm{P}<0.05,{ }^{* *} \mathrm{P}<0.01$ compared to the Control group.

Beclin1 overexpression inhibits cell viability in SW982 cells. The antitumor effect of Beclin1 has been confirmed in many tumor cells. To explore the function of Beclin1 in the viability of SW982 cells, a CCK-8 assay was used to detect the cell viability, an EdU cell proliferation assay was used to detect the synthesis of DNA, and a plate clone formation assay was performed to detect the proliferation ability. The result of the
CCK-8 assay showed that the viability of SW982 cells in the OE group was significantly inhibited (Fig. 2A). The EdU-positive rate was much lower in the $\mathrm{OE}$ group compared to the other groups (Fig. 2B). Meanwhile, the clones in the $\mathrm{OE}$ group had a significantly smaller mean diameter than those in the other two groups. However, there was no significant difference in the quantity of clones among the 3 groups (Fig. 2C). 
A

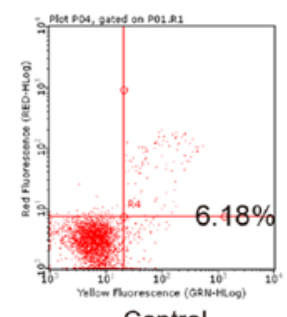

Control

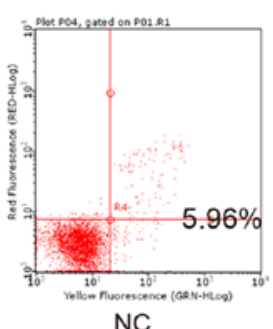

$\mathrm{NC}$

B

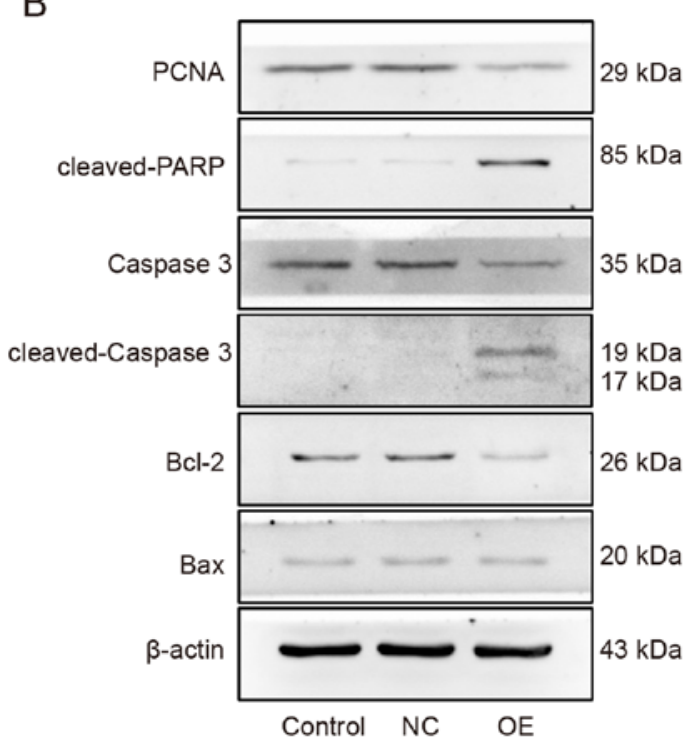

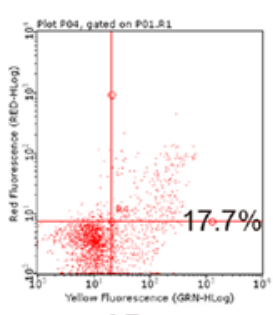

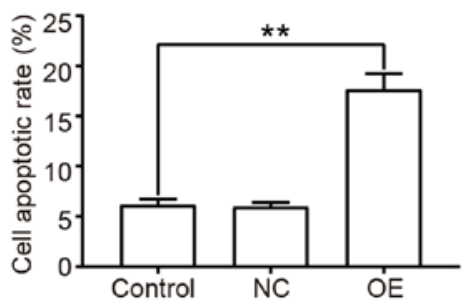

OE
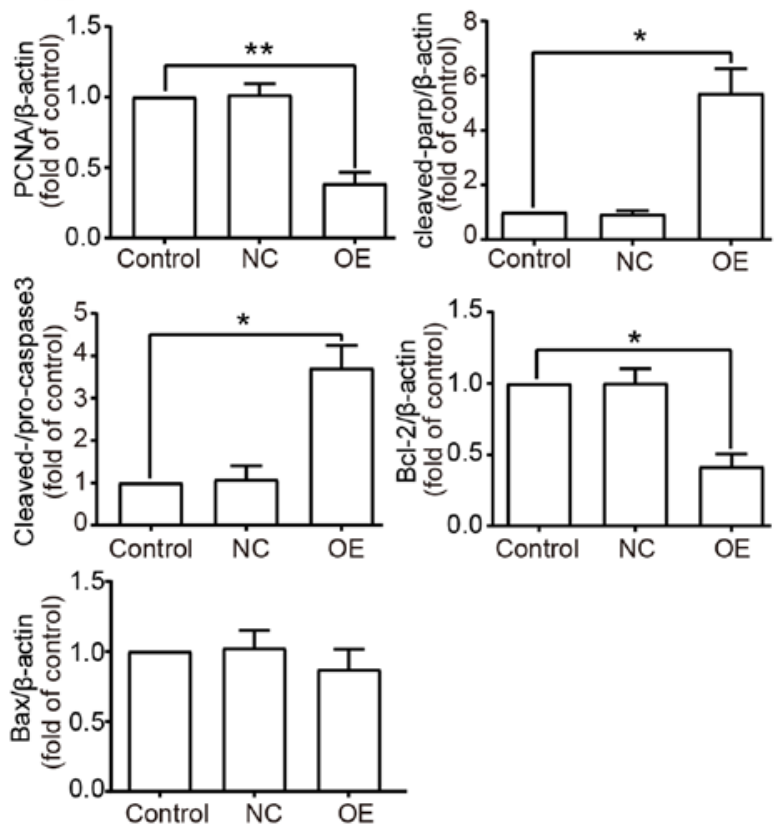

Figure 3. Beclin1 overexpression induces apoptosis in SW982 cells. (A) FCM analysis of apoptotic cells in the 3 groups: Control, NC (transfected with the negative control lentivirus) and $\mathrm{OE}$ (Beclin1-overexpressing). (B) Western blot analysis of apoptosis-related proteins in the 3 groups. ${ }^{*} \mathrm{P}<0.05$, ${ }^{* *} \mathrm{P}<0.01$ compared to the Control group.

Beclin1 overexpression induces apoptosis in the SW982 cells. To determine the apoptotic rate, flow cytometry (FCM) was performed, and the result showed that the apoptotic rate in the OE group was much higher than the rate in the other two groups (Fig. 3A). For further confirmation, western blot assays were performed to detect the expression levels of proteins such as PCNA, cleaved-PARP, cleaved-caspase-3, Bcl-2 and Bax. The result showed that the expression levels of PCNA and Bcl-2 were decreased, while the cleaved-PARP and cleaved-caspase- 3 were increased in the OE group. However, there was no difference in the expression level of the pro-apoptotic protein Bax among the 3 groups (Fig. 3B).

Beclin1 overexpression increases the autophagic activity in SW982 cells. It is commonly known that Beclin1 is a vital gene involved in the autophagy process. To explore the effect of Beclin1 overexpression on the autophagy in SW982 cells, the autophagy-related markers LC3 and p62 were detected by western blot assay. The results showed that the expression level of LC3II was increased and that of p62 was decreased in the OE group (Fig. 4A). To confirm that Beclin1 overexpression could increase the autophagic flux, Bafilomycin A1 (Baf A1) which is a specific autophagic inhibitor was applied to inhibit the degradation of autophagy-lysosomes. The results showed that the expression level of LC3II was further increased in the presence of $\mathrm{Baf} \mathrm{A} 1$, which indicated that Beclin1 overexpression enhanced the autophagic activity in SW982 cells (Fig. 4B). Moreover, the formation of autophagosomes was observed by transmission electron microscopy, and more double membrane-enclosed autophagic vesicles containing engulfed organelles were found in the SW982 cells of the OE group compared to the Control group (Fig. 4C).

Autophagy contributes to the reduction in cell viability in SW982 cells. To investigate the relationship between apoptosis and autophagy, both induced by Beclin1-overexpression, small interfering RNA (siRNA) targeting Atg5 was used to inhibit the expression of Atg5 to suppress the autophagic activity. The efficiency of inhibition was determined by RT-qPCR and western blot assay. The results showed that 2 \#siRNA and 3\#siRNA effectively suppressed the expression level of Atg5 (Fig. 5A and B). Therefore, 3\#siRNA which had the highest inhibition efficiency was used to knockdown Atg5 in SW982 cells of the OE group, and the Atg5-knockdown cells in the $\mathrm{OE}$ group were isolated as the OE-Atg5 group. Western blot assay showed that the expression level of LC3II was decreased, but the expression level of p62 was increased in the OE-Atg5 group (Fig. 5C). A CCK-8 assay was performed to detect the cell viability in each group, and the result demonstrated that the viability in the OE-Atg5 group was significantly increased compared to the OE group but lower than the viability of the Control and NC groups (Fig. 5D). EdU assay showed that there 

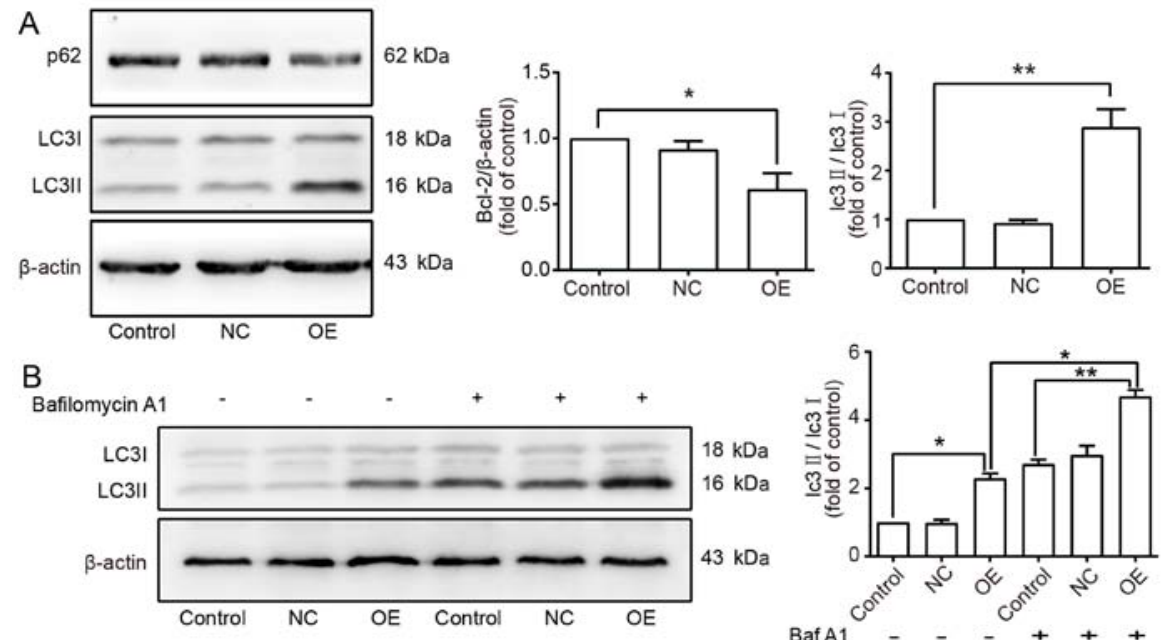

C
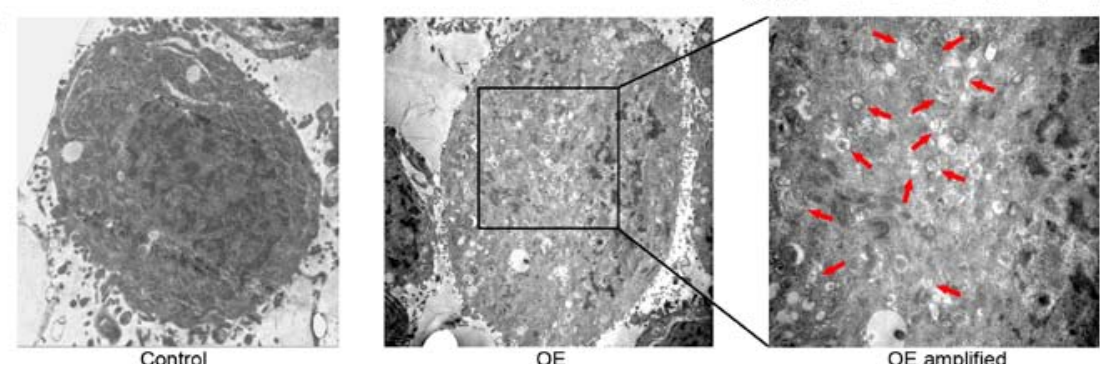

Figure 4. Beclin1 overexpression enhances autophagic activity in SW982 cells. (A) Western blot analysis of the autophagy-related proteins LC3 and p62 in the 3 groups: Control, NC (transfected with the negative control lentivirus) and OE (Beclin1-overexpressing). (B) Western blot analysis for autophagic flux test. (C) Autophagosome formation was observed via transmission electron microscopy (The red arrows indicate the autophagosomes). Control and OE: Magnification, $\mathrm{x} 4,000$; OE amplified: Magnification, $\mathrm{x} 10,000) .{ }^{*} \mathrm{P}<0.05,{ }^{* *} \mathrm{P}<0.01$.

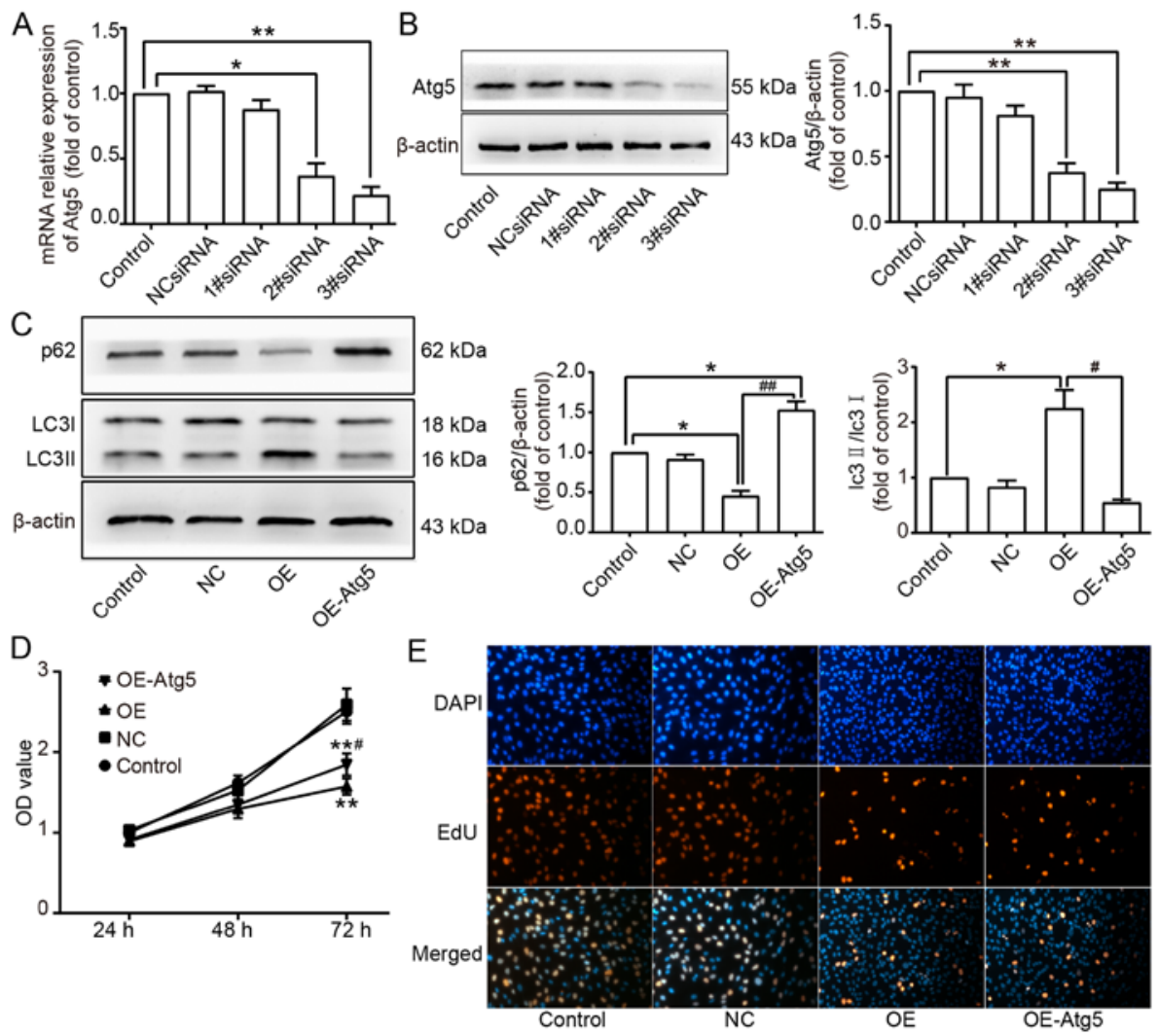

Figure 5. Autophagy contributes to the reduction in viability in SW982 cells. (A) RT-qPCR assay for autophagy-related gene Atg5 in the SW982 cells transfected with small interfering RNAs (siRNAs) targeting Atg5 (1\#siRNA, 2\#siRNA and 3\#siRNA) and NCsiRNA (negative control). (B) Western blot analysis for the expression of Atg5. (C) Western blot assay for the expression of p62 and LC3 in the 4 groups: Control, NC (transfected with the negative control lentivirus), OE (Beclin1-overexpressing) and OE-Atg5 (OE cells transfected with 3\#siRNA for Atg5) groups. (D) CCK-8 assay for detecting cell viability in the 4 groups. (E) EdU assay of the 4 groups (magnification, $\mathrm{x} 100$ ). ${ }^{*} \mathrm{P}<0.05,{ }^{* *} \mathrm{P}<0.01$ compared to the Control group; ${ }^{*} \mathrm{P}<0.05$, ${ }^{\# \#} \mathrm{P}<0.01$ compared to the OE group 

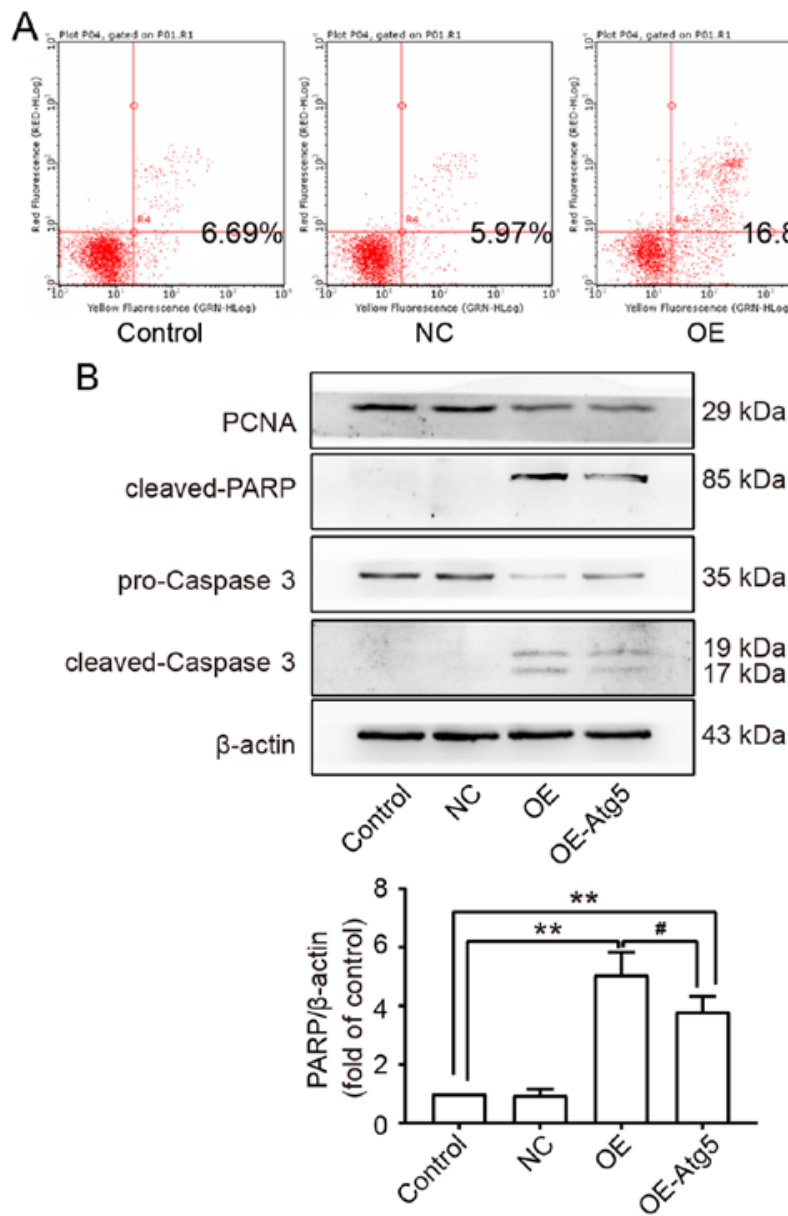

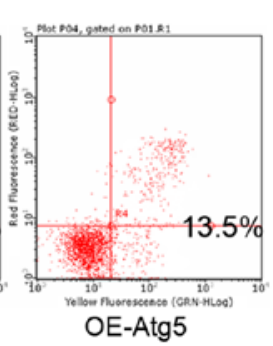

OE-Atg5
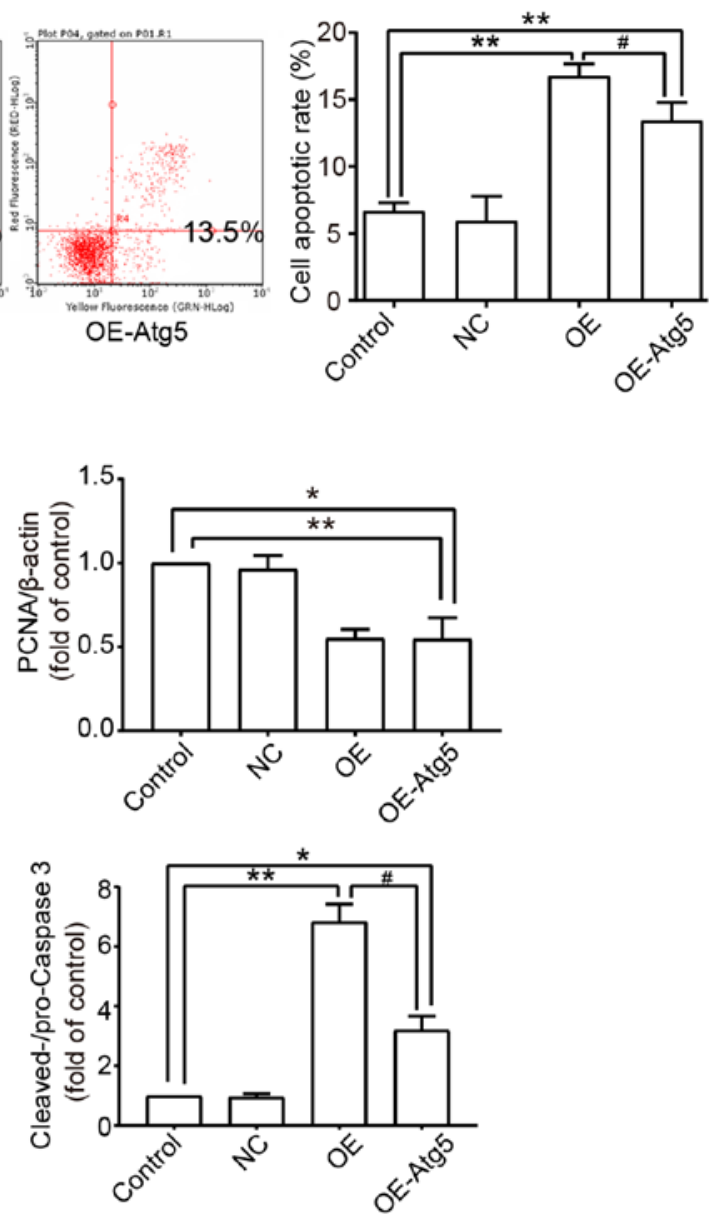

C
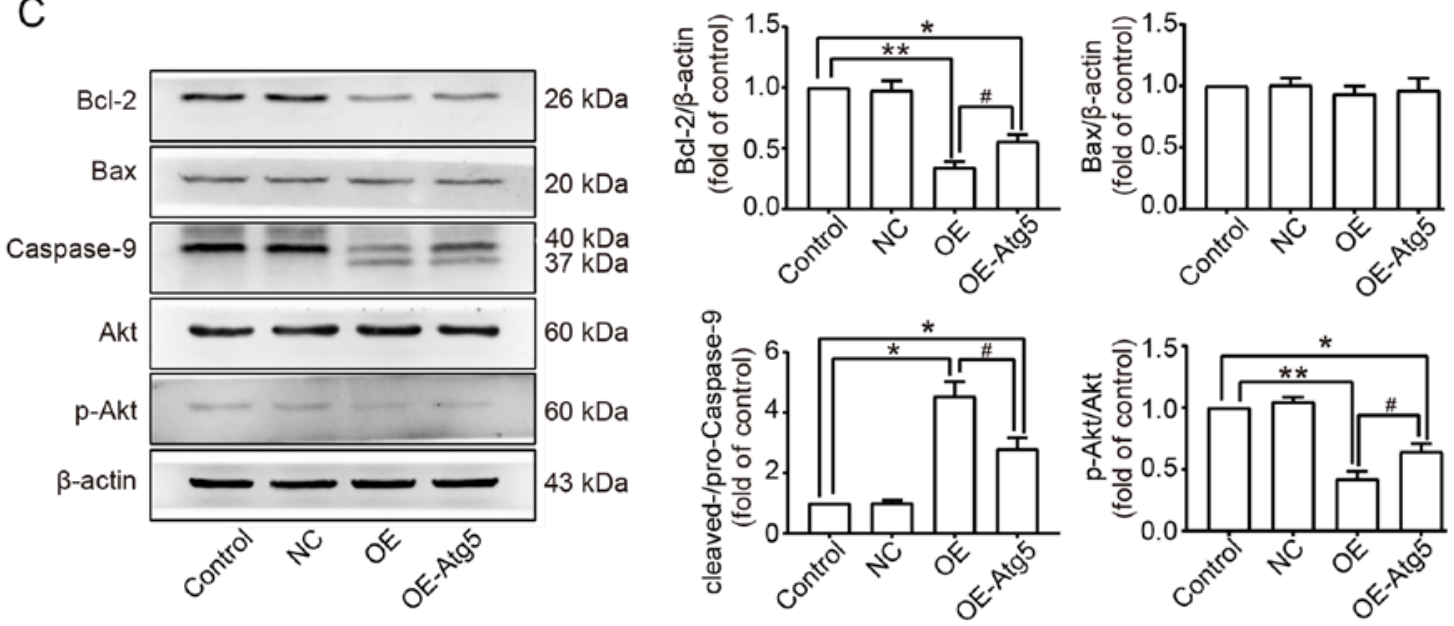

Figure 6. Autophagy promotes the apoptosis induced by Beclin1 overexpression through the Akt/Bcl-2/caspase-9 signaling pathway. (A) FCM analysis of apoptotic cells in the 4 groups: Control, NC (transfected with the negative control lentivirus), OE (Beclin1-overexpressing) and OE-Atg5 (OE cells transfected with 3\#siRNA forAtg5). (B) Western blot assay for PCNA, cleaved-PARP and cleaved-caspase-3. (C) Western blot assay for Bcl-2, Bax, caspase-9 and Akt. ${ }^{*} \mathrm{P}<0.05,{ }^{* *} \mathrm{P}<0.01$, compared to the Control group; \#P<0.05 compared to the OE group.

was no difference in the EdU-positive rate between the $\mathrm{OE}$ and OE-Atg5 groups (Fig. 5E).

Autophagy promotes the apoptosis induced by Beclin1 overexpression through the Akt/Bcl-2/caspase-9 signaling pathway. Since the relationship between apoptosis and autophagy remains unclear, FCM was performed to determine the change in the apoptotic rate when autophagy was inhibited. The result showed that inhibition of autophagy suppressed apoptosis induced by Beclin1 overexpression to some extent, but the effect was not absolutely reversed (Fig. 6A). This conclusion was confirmed by western blot assay; the expression levels of cleaved-PARP and cleaved-caspase-3 were both decreased in the OE-Atg5 group compared to the OE group, but no difference was found in the expression of PCNA between the $\mathrm{OE}$ and OE-Atg5 groups (Fig. 6B). Akt is an important gene involved in both apoptosis and autophagy through various signaling pathways; we further studied whether 
this pathway participated in the pathophysiological process mentioned above in SW982 cells. Western blot assays were performed, and related proteins were detected; the expression level of Bcl-2 was increased in the OE-Atg5 group compared to the OE group; no difference was found in the expression level of Bax among all groups. Activation of caspase-9 was enhanced in the OE group, and Atg5-knockdown inhibited this activation to a certain degree. Phosphorylation of Akt was inhibited in the OE group, and Atg5 knockdown reversed this inhibition (Fig. 6C).

\section{Discussion}

The antitumor effect of Beclin1 has been confirmed in many previous studies, and Beclin1 gene deletion has been found in ovarian (29-31), breast $(32,33)$, prostate $(34,35)$ and other tumors (36-39). However, the underlying mechanism of this phenomenon remains unclear, which has caused a lot of controversy.

In the present study, we demonstrated that Beclin1 overexpression inhibited cell viability and induced apoptosis. Beclin1 has a $\mathrm{BH} 3$ domain that binds to the anti-apoptotic protein Bcl-2 to undermine the anti-apoptotic ability of tumor cells. Bcl-2 is mainly expressed in proliferating and differentiating cells. However, high expression of Bcl-2 inhibits the apoptosis of tumor cells, which is closely associated with tumorigenesis and tumor progress (40). PCNA is closely related to cellular DNA synthesis. The expression level of PCNA can be regarded as an indicator of cell proliferation status. FCM assay demonstrated that Beclin1 overexpression induced apoptosis in SW982 cells. Western blot assay showed that Beclin1 overexpression decreased the expression levels of Bcl-2 and PCNA, and promoted the activation of caspase- 3 and PARP, but the expression level of Bax did not significantly change. We assumed that the reason for the decreased viability was the imbalance of Bcl-2/Bax, mainly because of the downregulation of Bcl-2. In addition, similar findings have been reported in previous studies (41-44). The result of the plate clone formation assay showed that Beclin1 overexpression inhibited cell proliferation. Notably, the OE group had a smaller mean diameter of clones due to the inhibition of proliferation, but there was no significant difference in the quantity of clones among the different groups. This result implied that Beclin1 did not simply kill the tumor cells, but functioned subtly to regulate cell proliferation and death within an appropriate range.

Under normal conditions, autophagy protects cells against pro-apoptotic factors $(45,46)$. However, autophagy can also play a role similar to apoptosis, leading to autophagic cell death in some cases. This biological process was named type II programmed cell death to distinguish it from apoptosis (47). In recent years, more and more cases of autophagic death have been reported, especially in tumors (24). Yu et al (48) found that Zinc oxide nanoparticles induced autophagic cell death and mitochondrial damage via the generation of reactive oxygen species. Li et al (49) found that plumbagin induced apoptotic and autophagic cell death through inhibition of the PI3K/Akt/mTOR pathway in human non-small cell lung cancer cells. Beclin1, as an important gene of autophagy, is related to both apoptosis and autophagy.
Mcl-1-dependent activation of Beclin1 mediated autophagic cell death induced by sorafenib and SC-59 in hepatocellular carcinoma cells (50). Zoledronate induced autophagic cell death in human umbilical vein endothelial cells via Beclin1 dependent pathway activation (25).

In this study, Beclin1 overexpression enhanced autophagic activity, and when the autophagic activity was inhibited by Atg5-knockdown, the cell viability was significantly increased. We assumed that Beclin1 overexpression induced autophagic death in SW982 cells. However, because the inhibition of autophagic activity did not absolutely reverse the cell death induced by Beclin1 overexpression, there may be an autophagy-independent pathway that led to cell death. The inhibition of autophagy did not change the expression level of the PCNA, which implied that Beclin1 could suppress the proliferation of SW982 in an autophagy-independent way. In addition, EdU assays confirmed this result mentioned above. Additionally, FCM assay and western blot analysis of the apoptosis-related proteins caspase-3 and PARP showed that the inhibition of autophagy also suppressed the apoptotic activity. It was reported that autophagy could result in cell death alone $(51,52)$, and autophagy could also induce cell death via activating apoptosis $(53,54)$. Moreover, we also found that Akt/Bcl-2/caspase-9 pathway was involved in the cell death induced by Beclin1 overexpression, and it is known that Akt affects both apoptosis and autophagy (55).

Autophagy is a double-edged sword for cell fate, and its definite mechanism remains unclear. The role of Beclin1 in the crosstalk between autophagy and apoptosis needs further exploration. Altogether, the present study revealed the critical antitumor effect of Beclin1 in the SW982 synovial sarcoma cells, suggesting that Beclin1 might be an important target for synovial sarcoma therapy. SW982 is one kind of synovial sarcoma cell lines, which is most commonly used in studies because of its stable biological characteristics. All of the results in this study were observed in SW982 synovial sarcoma cells. Different cell lines of synovial sarcoma vary in the biological characteristics, it would be better to use more than 2 different cell lines to make the conclusion. However, SW982 is the only cell line that can be obtained from the ATCC bioresource center, and it is also the only synovial sarcoma cell line exists in China over the course of this study. We will use other synovial sarcoma cell lines or primary synovial sarcoma cells to verified our present result in further studies.

\section{Acknowledgements}

We wish to thank Dr Liang Bai for the technical advice.

\section{Funding}

The present study was supported by the National Natural Science Foundation of China (grant nos. 81271948, 81601877 and 81171742).

\section{Availability of data and materials}

The datasets used during the present study are available from the corresponding author upon reasonable request. 


\section{Authors' contributions}

JZ, PX, SL and JC conceived, designed and performed the experiments. YC and KX analyzed the data. XR and JS performed the electron microscopy analysis. JZ wrote the manuscript. All authors read and approved the manuscript and agree to be accountable for all aspects of the research in ensuring that the accuracy or integrity of any part of the work are appropriately investigated and resolved.

\section{Ethics approval and consent to participate}

Not applicable.

\section{Patient consent for publication}

Not applicable.

\section{Competing interests}

The authors declare that they have no competing interests.

\section{References}

1. Yaser S, Salah S, Al-Shatti M, Abu-Sheikha A, Shehadeh A, Sultan I, Salem A, Sughayer M, Al-Loh S and Al-Mousa A: Prognostic factors that govern localized synovial sarcoma: A single institution retrospective study on 51 patients. Med Oncol 31: 958, 2014

2. El Beaino M, Araujo DM, Gopalakrishnan V, Lazar AJ and Lin PP: Prognosis of T1 synovial sarcoma depends upon surgery by oncologic surgeons. J Surg Oncol 114: 490-494, 2016.

3. Levine B and Klionsky DJ: Development by self-digestion: Molecular mechanisms and biological functions of autophagy. Dev Cell 6: 463-477, 2004

4. Wen YF, Zand B, Ozpolat B, Szczepanski MJ, Lu CH, Yuca E, Carroll AR, Alpay N, Bartholomeusz C, Tekedereli I, et al Antagonism of tumoral prolactin receptor promotes autophagyrelated cell death. Cell Rep 7: 488-500, 2014

5. Galluzzi L, Pietrocola F, Bravo-San Pedro JM, Amaravadi RK, Baehrecke EH, Cecconi F, Codogno P, Debnath J, Gewirtz DA, Karantza V, et al: Autophagy in malignant transformation and cancer progression. EMBO J 34: 856-880, 2015.

6. Liang XH, Kleeman LK, Jiang HH, Gordon G, Goldman JE, Berry G, Herman B and Levine B: Protection against fatal Sindbis virus encephalitis by Beclin, a novel Bcl-2-interacting protein. J Virol 72: 8586-8596, 1998.

7. Oberstein A, Jeffrey PD and Shi YG: Crystal structure of the Bcl-XL-Beclin 1 peptide complex: Beclin 1 is a novel BH3-only protein. J Biol Chem 282: 13123-13132, 2007.

8. Park JM, Tougeron D, Huang S, Okamoto K and Sinicrope FA: Beclin 1 and UVRAG confer protection from radiation-induced DNA damage and maintain centrosome stability in colorectal cancer cells. PLoS One 9: e100819, 2014.

9. Wang W, Fan H, Li X, Wu G, Zhao W, Zhang G, Zhao G and Li L: Beclin 1 promotes apoptosis and decreases invasion by upregulating the expression of ECRG4 in A549 human lung adenocarcinoma cells. Mol Med Report 14: 355-360, 2016.

10. De Amicis F, Aquila S, Morelli C, Guido C, Santoro M, Perrotta I, Mauro L, Giordano F, Nigro A, Andò S, et al: Bergapten drives autophagy through the up-regulation of PTEN expression in breast cancer cells. Mol Cancer 14: 130, 2015.

11. Jung YY, Lee YK and Koo JS: The potential of Beclin 1 as a therapeutic target for the treatment of breast cancer. Expert Opin Ther Targets 20: 167-178, 2016.

12. Wu S, Sun C, Tian D, Li Y, Gao X, He S and Li T: Expression and clinical significances of Beclin1, LC3 and mTOR in colorectal cancer. Int J Clin Exp Pathol 8: 3882-3891, 2015.

13. Chen Z, Li Y, Zhang C, Yi H, Wu C, Wang J, Liu Y, Tan J and Wen J: Downregulation of Beclin 1 and impairment of autophagy in a small population of colorectal cancer. Dig Dis Sci 58: 2887-2894, 2013.
14. Hu YF, Lei X, Zhang HY, Ma JW, Yang WW, Chen ML, Cui $\mathrm{J}$ and Zhao H: Expressions and clinical significance of autophagy-related markers Beclin1, LC3, and EGFR in human cervical squamous cell carcinoma. Onco Targets Ther 8: 2243-2249, 2015.

15. Chen Z, Wang B, Yu F, Chen Q, Tian Y, Ma S and Liu X: The roles of mitochondria in radiation-induced autophagic cell death in cervical cancer cells. Tumour Biol 37: 4083-4091, 2016.

16. Ju LL, Zhao CY, Ye KF, Yang $\mathrm{H}$ and Zhang J: Expression and clinical implication of Beclin1, HMGB1, p62, survivin, BRCA1 and ERCC1 in epithelial ovarian tumor tissues. Eur Rev Med Pharmacol Sci 20: 1993-2003, 2016.

17. Cai M, Hu Z, Liu J, Gao J, Liu C, Liu D, Tan M, Zhang D and Lin B: Beclin 1 expression in ovarian tissues and its effects on ovarian cancer prognosis. Int J Mol Sci 15: 5292-5303, 2014.

18. Xue S, Xiao-Hong S, Lin S, Jie B, Li-Li W, Jia-Yao G, Shun S, Pei-Nan L, Mo-Li W, Qian W, et al: Lumbar puncture-administered resveratrol inhibits STAT3 activation, enhancing autophagy and apoptosis in orthotopic rat glioblastomas. Oncotarget 7 : 75790-75799, 2016.

19. Huang X, Qi Q, Hua X, Li X, Zhang W, Sun H, Li S, Wang X and Li B: Beclin 1, an autophagy-related gene, augments apoptosis in U87 glioblastoma cells. Oncol Rep 31: 1761-1767, 2014.

20. Bai H, Li H, Li W, Gui T, Yang J, Cao D and Shen K: The $\mathrm{PI} 3 \mathrm{~K} / \mathrm{AKT} / \mathrm{mTOR}$ pathway is a potential predictor of distinct invasive and migratory capacities in human ovarian cancer cell lines. Oncotarget 6: 25520-25532, 2015.

21. Katagiri H, Nakayama K, Razia S, Nakamura K, Sato E, Ishibashi T, Ishikawa M, Iida K, Ishikawa N, Otsuki Y, et al: Loss of autophagy-related protein Beclin 1 may define poor prognosis in ovarian clear cell carcinomas. Int $\mathrm{J}$ Oncol 47: 2037-2044, 2015.

22. Garbar C, Mascaux C, Giustiniani J, Salesse S, Debelle L, Antonicelli F, Merrouche Y and Bensussan A: Autophagy is decreased in triple-negative breast carcinoma involving likely the MUC1-EGFR-NEU1 signalling pathway. Int J Clin Exp Pathol 8: 4344-4355, 2015.

23. Rohatgi RA, Janusis J, Leonard D, Bellvé KD, Fogarty KE, Baehrecke EH, Corvera S and Shaw LM: Beclin 1 regulates growth factor receptor signaling in breast cancer. Oncogene 34: 5352-5362, 2015.

24. Shimizu S, Yoshida T, Tsujioka M and Arakawa S: Autophagic cell death and cancer. Int J Mol Sci 15: 3145-3153, 2014.

25. Lu Y, Wang Z, Han W and Li H: Zoledronate induces autophagic cell death in human umbilical vein endothelial cells via Beclin-1 dependent pathway activation. Mol Med Report 14: 4747-4754, 2016.

26. Elgendy M, Ciro M, Abdel-Aziz AK, Belmonte G, Dal Zuffo R, Mercurio C, Miracco C, Lanfrancone L, Foiani M and Minucci S: Beclin 1 restrains tumorigenesis through Mcl-1 destabilization in an autophagy-independent reciprocal manner. Nat Commun 5: 5637, 2014.

27. Rohatgi RA and Shaw LM: An autophagy-independent function of Beclin 1 in cancer. Mol Cell Oncol 3: pii: e1030539, 2016.

28. Livak KJ and Schmittgen TD: Analysis of relative gene expression data using real-time quantitative PCR and the $2^{-\Delta \Delta C_{\mathrm{T}}}$ method. Methods 25: 402-408, 2001.

29. Correa RJ, Valdes YR, Shepherd TG and DiMattia GE: Beclin-1 expression is retained in high-grade serous ovarian cancer yet is not essential for autophagy induction in vitro. J Ovarian Res 8: $52,2015$.

30. Wang YF, Xu YL, Tang ZH, Li T, Zhang LL, Chen X, Lu JH, Leung CH, Ma DL, Qiang WA, et al: Baicalein induces Beclin 1and extracellular signal-regulated kinase-dependent autophagy in ovarian cancer cells. Am J Chin Med 45: 123-136, 2017.

31. Ying H, Qu D, Liu C, Ying T, Lv J,Jin S and Xu H: Chemoresistance is associated with Beclin-1 and PTEN expression in epithelial ovarian cancers. Oncol Lett 9: 1759-1763, 2015.

32. Li WL, Xiong LX, Shi XY, Xiao L, Qi GY and Meng C: IKK $\beta / N F x B$ p65 activated by interleukin-13 targets the autophagy-related genes LC3B and beclin 1 in fibroblasts co-cultured with breast cancer cells. Exp Ther Med 11: 1259-1264, 2016.

33. De Amicis F, Guido C, Santoro M, Giordano F, Donà A, Rizza $P$, Pellegrino M, Perrotta I, Bonofiglio D, Sisci D, et al: Ligand activated progesterone receptor $\mathrm{B}$ drives autophagy-senescence transition through a Beclin-1/Bcl-2 dependent mechanism in human breast cancer cells. Oncotarget 7: 57955-57969, 2016. 
34. Baspinar S, Bircan S, Orhan H, Kapucuoglu N and Bozkurt KK: The relation of beclin 1 and bcl-2 expressions in high grade prostatic intraepithelial neoplasia and prostate adenocarcinoma: A tissue microarray study. Pathol Res Pract 210: 412-418, 2014.

35. Lian J, Wu X, He F, Karnak D, Tang W, Meng Y, Xiang D, Ji M, Lawrence TS and Xu L: A natural $\mathrm{BH} 3$ mimetic induces autophagy in apoptosis-resistant prostate cancer via modulating Bcl-2-Beclin1 interaction at endoplasmic reticulum. Cell Death Differ 18: 60-71, 2011.

36. Jung G, Roh J, Lee H, Gil M, Yoon DH, Suh C, Jang S, Park CJ, Huh J and Park CS: Autophagic markers BECLIN 1 and LC3 are associated with prognosis of multiple myeloma. Acta Haematol 134: 17-24, 2015.

37. Fukui M, Yamabe N, Choi HJ, Polireddy K, Chen Q and Zhu BT: Mechanism of ascorbate-induced cell death in human pancreatic cancer cells: Role of Bcl-2, Beclin 1 and autophagy. Planta Med 81: 838-846, 2015.

38. Al-Shenawy HA: Expression of Beclin-1, an autophagy-related marker, in chronic hepatitis and hepatocellular carcinoma and its relation with apoptotic markers. APMIS 124: 229-237, 2016.

39. Ma K, Zhang C, Huang MY, Guo YX and Hu GQ: Crosstalk between Beclin-1-dependent autophagy and caspase-dependent apoptosis induced by tanshinone IIA in human osteosarcoma MG-63 cells. Oncol Rep 36: 1807-1818, 2016.

40. Sun C, Liu Z, Li S, Yang C, Xue R, Xi Y, Wang L, Wang S, He Q, Huang J, et al: Down-regulation of c-Met and Bcl2 by microRNA-206, activates apoptosis, and inhibits tumor cell proliferation, migration and colony formation. Oncotarget 6: 25533-25574, 2015.

41. Liu LS, Bai XQ, Gao Y, Wu Q, Ren Z, Li Q, Pan LH, He NY, Peng $\mathrm{J}$ and Tang ZH: PCSK9 promotes oxLDL-induced PC12 cell apoptosis through the Bcl-2/Bax-Caspase 9/3 signaling pathway. J Alzheimers Dis 57: 723-734, 2017.

42. Lončarević-Vasiljković N, Milanović D, Pešić V, Tešić V, Brkić M, Lazić D, Avramović V and Kanazir S: Dietary restriction suppresses apoptotic cell death, promotes Bcl-2 and Bcl-xl mRNA expression and increases the Bcl-2/Bax protein ratio in the rat cortex after cortical injury. Neurochem Int 96: 69-76, 2016.

43. Song S, Jacobson KN, McDermott KM, Reddy SP, Cress AE, Tang HY, Dudek SM, Black SM, Garcia JG, Makino A, et al: ATP promotes cell survival via regulation of cytosolic $[\mathrm{Ca} 2+]$ and $\mathrm{Bcl}-2 / \mathrm{Bax}$ ratio in lung cancer cells. Am J Physiol Cell Physiol 310: C99-C114, 2016.

44. Jiang N, Li Y and Ruan DY: Sa1688 aberrantly regulated dysadherin and Bcl-2/Bax2 enhances tumorigenesis and DNA targeting drug resistance of liver cancer stem cells. Gastroenterology 148 S1012-S1012, 2015.

45. Cai Y, Xu P, Yang L, Xu K, Zhu J, Wu X, Jiang C, Yuan Q, Wang B, Li Y, et al: HMGB1-mediated autophagy decreases sensitivity to oxymatrine in SW982 human synovial sarcoma cells. Sci Rep 6: 37845, 2016
46. Xu K, Cai YS, Lu SM, Li XL, Liu L, Li Z, Liu H and Xu P. Autophagy induction contributes to the resistance to methotrexate treatment in rheumatoid arthritis fibroblast-like synovial cells through high mobility group box chromosomal protein 1. Arthritis Res Ther 17: 374, 2015.

47. Liu Y and Levine B: Autosis and autophagic cell death: The dark side of autophagy. Cell Death Differ 22: 367-376, 2015.

48. Yu KN, Yoon TJ, Minai-Tehrani A, Kim JE, Park SJ, Jeong MS, Ha SW, Lee JK, Kim JS and Cho MH: Zinc oxide nanoparticle induced autophagic cell death and mitochondrial damage via reactive oxygen species generation. Toxicol In Vitro 27: 1187-1195, 2013.

49. Li YC, He SM, He ZX, Li M, Yang Y, Pang JX, Zhang X, Chow K Zhou Q, Duan W, et al: Plumbagin induces apoptotic and autophagic cell death through inhibition of the PI3K/Akt/mTOR pathway in human non-small cell lung cancer cells. Cancer Lett 344: 239-259, 2014.

50. Tai WT, Shiau CW, Chen HL, Liu CY, Lin CS, Cheng AL, Chen PJ and Chen KF: Mcl-1-dependent activation of Beclin 1 mediates autophagic cell death induced by sorafenib and SC-59 in hepatocellular carcinoma cells. Cell Death Dis 4: e485, 2013.

51. Wong VK, Li T, Law BY, Ma ED, Yip NC, Michelangeli F, Law CK, Zhang MM, Lam KY, Chan PL, et al: Saikosaponin-d, a novel SERCA inhibitor, induces autophagic cell death in apoptosis-defective cells. Cell Death Dis 4: e720, 2013.

52. Liu C, Yan X, Wang HQ, Gao YY, Liu J, Hu Z, Liu D, Gao J and Lin B: Autophagy-independent enhancing effects of Beclin 1 on cytotoxicity of ovarian cancer cells mediated by proteasome inhibitors. BMC Cancer 12: 622, 2012.

53. Lamy L, Ngo VN, Emre NC, Shaffer AL III, Yang Y, Tian E, Nair V, Kruhlak M, Zingone A, Landgren O, et al: Control of autophagic cell death by caspase-10 in multiple myeloma. Cancer Cell 23: 435-449, 2013.

54. Yu FS, Yu CS, Chen JC, Yang JL, Lu HF, Chang SJ, Lin MW and Chung JG: Tetrandrine induces apoptosis Via caspase- $8,-9$, and -3 and poly (ADP ribose) polymerase dependent pathways and autophagy through beclin-1/ LC3-I, II signaling pathways in human oral cancer HSC-3 cells. Environ Toxicol 31: 395-406, 2016.

55. Zhao ZQ, Yu ZY, Li J and Ouyang XN: Gefitinib induces lung cancer cell autophagy and apoptosis via blockade of the PI3K/AKT/mTOR pathway. Oncol Lett 12: 63-68, 2016. 